\title{
Far-field method for the characterisation of three-dimensional fields: vectorial polarimetry
}

\author{
O. Rodríguez ${ }^{1}$, D. Lara ${ }^{2}$ and C. Dainty ${ }^{1}$
}

${ }^{1}$ Applied Optics, National University of Ireland, Galway, Ireland

${ }^{2}$ The Blackett Laboratory, Imperial College London, SW7 2BW, London, United Kingdom

\begin{abstract}
The first attempt to completely characterie a three-dimensional field was done by Ellis and Dogariu with ex cellent results reported [1] . However, their method is based on near-field techn iques, which limits its range of applications. In this work, we present an alternative far-field method for the characterisation of the three-d imensional field that results from the inte raction of a tightly focused three-dimensional field [2] with a sub-resolution specimen. $\mathrm{Ou} \quad \mathrm{r}$ method is based on th e analy sis of the scattering- angle-resolved polarisation state distr ibution across th e ex it pu pil of a high $n$ umerical ap erture (NA) co llector lens using standard polarimetry techniques. Details of the $\mathrm{m}$ ethod, the experimental setup built to verif $\mathrm{y}$ its capabilities, and num erical and first experim ental evidence demonstrating th at the $m$ ethod allows for high sensitivit $y$ on sub-resolution displacements of a s ub-resolution specimen shall be presented [ 3]. This work i s funded b y Science Foundation Ireland gr ant No. 07/ IN.1/1906 and Shimadzu Corporatio n, Japan. Oscar Rodríguez is grateful to the National Council for Science an d Technology (CONACYT, Mexico) for the Ph D scholarship 177627.
\end{abstract}

\section{References}

1. J. Ellis and A. Dogariu, Phys. Rev. Lett., 95, 203905 (2005)

2. B. Richards and E. Wolf, Proc. R. Soc. London A, 253, 358 (1959)

3. A. E. Elsner, S. A. Burns, J. J. Weiter and F. C. Delori, Vision Research, 36, 191 (1996)

4. O. Rodríguez, PhD. thesis (National University of Galway, 2009) 